\title{
DIMENSIONAL ACCURACY OF PUTTY-WASH ONE-STEP AND TWO-STEP IMPRESSION TECHNIQUE IN FABRICATION OF FIXED PARTIAL DENTURE
}

\author{
Fernando ${ }^{1}$, Syafrinani2 ${ }^{2}$ Indra Nasution ${ }^{3}$ \\ 1 Postgraduate Program in Prosthodontics, Faculty of Dentistry, Universitas Sumatera Utara, Medan, Indonesia. \\ ${ }^{2}$ Lecturer at Department of Prosthodontics, Faculty of Dentistry, Universitas Sumatera Utara, Medan, Indonesia. \\ ${ }^{3}$ Lecturer at Department of Mechanical Engineering, Faculty of Engineering, Universitas Sumatera Utara, Medan, Indonesia.
}

\section{ABSTRACT}

\section{BACKGROUND}

Impression is crucial step in fabrication of fixed partial denture (FPD). The most common impression technique used in fabric ation of fixed partial denture (FPD) is putty-wash impression technique, divided into two, which are one step and two step. Dimensional accuracy of one step and two step putty-wash impression technique is still a controversial. The purpose of this study is to find out the impression results difference of dimensional accuracy, inter abutment distance, abutment height, and mesiodistal width among conventional one step technique, modified one step technique with ethyl vinyl acetate spacer, non-spacer two step technique and two step technique with polyethylene spacer.

\section{METHODS}

The design of this study is laboratory experimental. Samples of this study are dye model from master model imprinted with polyvinyl siloxane putty and wash poured with type IV gypsum. The size of the master model is $28,25 \mathrm{~mm}$ for inter abutment distance, $8 \mathrm{~mm}$ for abutment height and $6,25 \mathrm{~mm}$ for mesiodistal width. 40 samples are divided into four groups, which are conventional one step technique group, modified one step technique with ethyl vinyl acetate spacer group, non-spacer two step technique group and two step technique with polyethylene spacer group. The samples are fabricated at Unit Jasa Industri (UJI) Dental FKG USU, the samples are scanned at Laboratorium Simon Dental Medan and measured with 3D Builder software. The samples are measured according to ISO No. 4823 in three dimension which are inter-abutment distance, abutment height and abutment mesiodistal width.

\section{RESULTS}

Mean and standard deviation for group A is $-0,216 \pm 0,127 \%$, group B is $0,177 \pm 0,11 \%$, group C is $0,57 \pm 0,213 \%$, and group D is $0,375 \pm 0,141 \%$. The mean and standard deviation abutment height for group A is $0,575 \pm 0,271 \%$, group $B$ is $0,013 \pm 0,26 \%$, group $\mathrm{C}$ is $0,55 \pm 0,179 \%$ and group $\mathrm{D}$ is $-0,85 \pm 0,444 \%$. The mean and standard deviation mesiodistal width for group $\mathrm{A}$ is $-1,54 \pm 0,28 \%$, group $B$ is $0,08 \pm 0,173 \%$, group $C$ is $-1,168 \pm 0,534 \%$ and group $D$ is $-0,72 \pm 0,513 \%$.

\section{CONCLUSIONS}

Modified one step technique with ethyl vinyl acetate spacer is the most accurate technique in inter-abutment distance, abutment height and mesiodistal width and the accuracy of that technique had significant difference with other techniques.

HOW TO CITE THIS ARTICLE: Fernando, Syafrinani, Nasution I. Dimensional accuracy of putty-wash one-step and two-step impression technique in fabrication of fixed partial denture. J. Evolution Med. Dent. Sci. 2019;8(13):988-994, DOI: $10.14260 /$ jemds/2019/221

\section{BACKGROUND}

The success of fixed partial denture depends on various procedures at the clinic. Impression is the most crucial step in fabrication of fixed partial denture (FPD). All of the oral tissue details must be recorded in impression. The accurate impression can produce high accuracy working model in horizontal and vertical dimension. In getting an accurate impression result, there are some factors to be concerned about such as the type of impression tray, the impression technique and the impression material. ${ }^{1-9}$ Final impression for FPG usually taken out using elastomer material. According to ADA specification no 19 , elastomer is divided into four groups according to the chemical composition and

'Financial or Other Competing Interest': None.

Submission 14-11-2018, Peer Review 17-03-2019,

Acceptance 23-03-2019, Published 01-04-2019.

Corresponding Author:

Fernando,

Jalan Alumni No. 2,

Universitas Sumatera Utara,

Medan, Indonesia.

E-mail: prostodonsia@gmail.com

DOI: $10.14260 /$ jemds $/ 2019 / 221$ polymerization reaction, they are polysulfide, polyether, condensation silicone and addition silicone. The dimensional stability of impression material is the ability of the material to maintain the accuracy of the impression. According to ADA Specification no 19, elastomer material has to obtain details up to $25 \mu \mathrm{m}$ or less. Polysulfide material is used to obtain details of the surface, but it does not have dimensional stability when it must be kept for long time. Polyether is a rigid hydrophilic material with a high modulus elasticity, but it is more expensive, short working time and setting time and to rigid once it is set.2,3

Polyvinyl siloxane is a silicone base impression material which has been modified from condensation silicone with poly-dimethyl silicone polymer compound. Addition silicone (Polyvinyl siloxane) does not produce any by product after polymerization reaction. So, it will maintain the dimensional stability. Polyvinyl siloxane also has the lowest distortion when it is removed compared to other elastomer material which make the accuracy of polyvinyl siloxane better. Leao et al stated that polyvinyl siloxane stays stable after 7 days impression is taken and after the first pour. This material does not smell, does not taste and comfortable for patient. 
The only disadvantage of this material is the inability to contact with latex gloves. ${ }^{2,3}$

Polyvinyl siloxane available in some viscosity, from the lowest to the highest which vary the technique of impression. Polyvinyl siloxane impression technique can be categorized into mono-phase (One step technique using one type of viscosity) and dual phase (One or two step using two types of impression materials with different viscosity like putty-wash technique and heavy body-wash technique). Still in controversy about the best impression technique in fabrication of FPD. Putty-wash impression technique can be done in one step or two step. One step putty-wash impression technique is a technique that the polymerization of both materials occurs at the same time so that we can save chairside time and materials, but the manipulation is a little bit difficult because the clinician has to handle two materials in the same time. The one step putty-wash impression technique can be divided into two, which are conventional and modification. Two step putty-wash impression technique is a technique where the higher viscosity material is used as a tray for the lower viscosity materials and the polymerization does not happen in the same time. Although this two-step technique commonly used and can produce accurate impression result, but there are few problems like dimensional changes, longer chairside time, and more materials needed to make impression. This two-step technique can be divided into two, which are two step without spacer (Escape groove) and with spacer (Polyethylene ) 1,2,3,7

Dimensional accuracy measurement of polyvinyl siloxane is done in 3 dimensions, such as mesiodistal width, abutment height and inter-abutment distance according to ISO no 4823:2015. Measurement can be done using some methods, one of them is using digital instrument. Digital dentistry consists of three parts, which are 3D Scanner, CAD (Computer aided design), and CAM (Computer aided manufacturing). 3D Scanners digitalize the working model. CAD is a software to design and modify restoration in computer meanwhile CAM is a milling machine used to produce restoration from the design. 10 In this study, the author want to find out the whether there is a dimensional accuracy difference among one step conventional putty-wash impression technique, one step modification, two step without spacer and two step with spacer polyethylene in working model fabrication.

\section{METHODS}

This study, an experimental laboratory study, used a stainless-steel master model consists of two abutments which has the same shape with full crown preparation. These abutments are $8^{\circ}$ conical shape with $6,25 \mathrm{~mm}$ mesiodistal width, $8 \mathrm{~mm}$ of abutments height and $28,25 \mathrm{~mm}$ of interabutments distance according to ANSI/ADA specification.
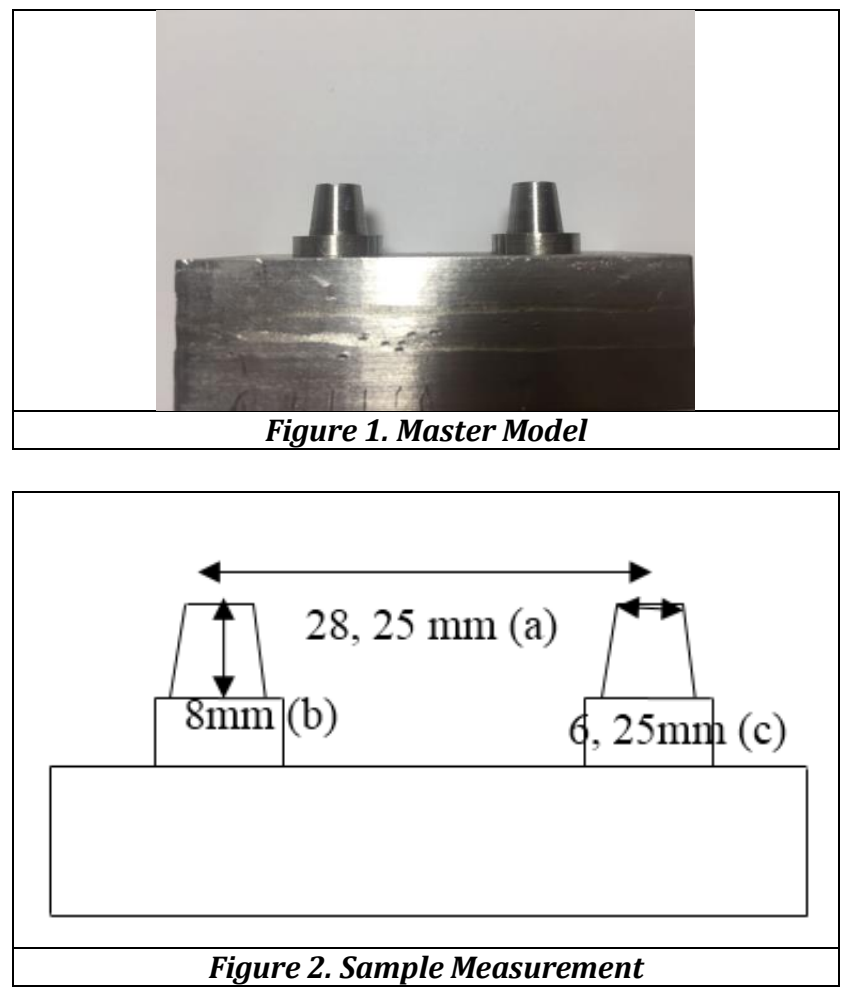

Polyvinyl siloxane with putty viscosity (Exaflex, GC, America) and wash viscosity (Examix, GC, America) were mixed according to manufacturer instruction and impression was taken out on master model with relative temperature and humidity $\left(23^{\circ} \mathrm{C} \pm 2^{\circ} \mathrm{C}\right.$ and $\left.50 \% \pm 10 \%\right)$

40 samples are divided into four groups, which are group A (One step conventional putty-wash impression technique). Putty materials were imprint together with wash material which had been injected around the master model. Group B (One step modification putty-wash impression technique), where the putty was imprint first at master model after ethyl vinyl acetate spacer was put on it and after one minute, the putty was taken out and the spacer was removed, then wash was injected, and putty was put back on master model. Group C (Two step without spacer putty-wash impression technique) where putty was imprinted first, then after setting, putty was removed and make groove on the putty and wash was injected and putty was put back on master model. Group D (Two step with polyethylene putty-wash impression technique) where the polyethylene spacer was put on master model first, then putty impression was taken. After setting, the spacer was removed, and wash injected then the putty was put back on the master model.

The impression result was poured with stone gips type IV (Fujirock, GC, America) with w/p ratio is $20 \mathrm{ml} 100 \mathrm{~g}$ (1:5). Then the samples were scanned (Identica Blue Medit, South Korea) and were measured with 3D Builder application (Microsoft, America) which are mesiodistal width, abutments height and inter-abutment distance. 

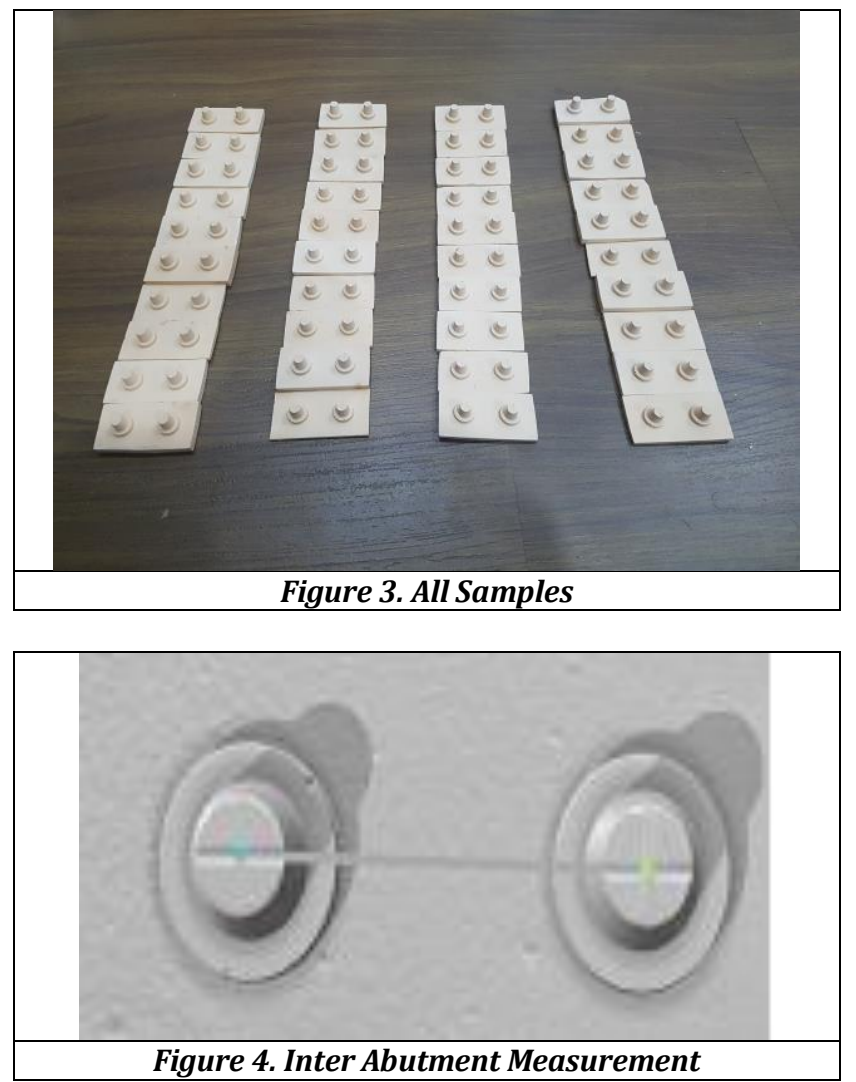
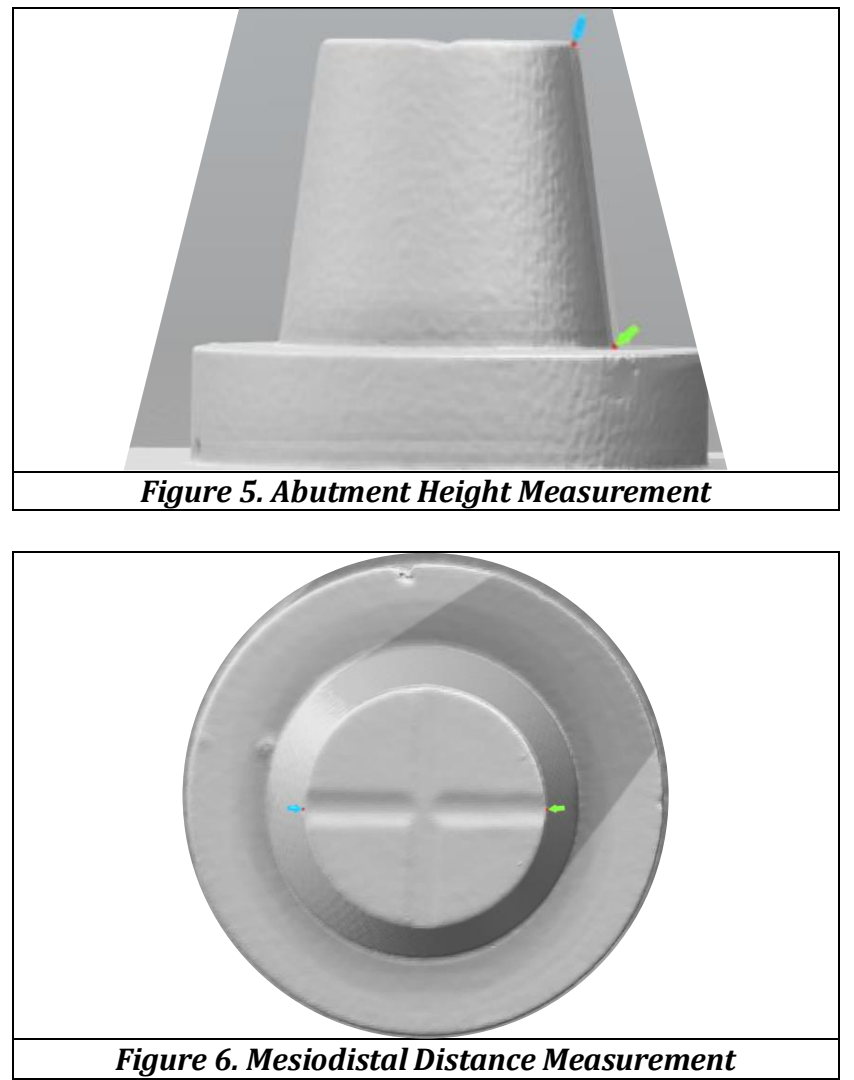

Then the Result Converted into Percentage with Formula-

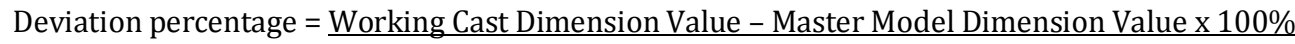
Master Model Dimension Model

Whereas, the positive value meant that there was increase in working cast dimension compared to master model and negative value meant that there was decrease in working cast dimension compared to master model.

Statistical analysis used in this study are ANOVA one way and LSD test to find out dimensional accuracy among groups. The statistical tool used to analysis the result is SPSS 22.0 (IBM Corp)

\section{RESULTS}

\section{Mesiodistal Width}

Mesiodistal width dimensional accuracy of group A showed the most inaccurate value was $-1,92 \%$, meanwhile the most accurate was $-1,12 \%$. For group B, the most inaccurate was $0,32 \%$ and the most accurate was $0 \%$. For group $C$, the most inaccurate was $-1,76 \%$, meanwhile the most accurate $-0,32 \%$. For group D, the most inaccurate was $-1,44 \%$ and the most accurate was $0 \%$. The mean and standard deviation for group A was $-1,54 \pm 0,28 \%$. The mean and standard deviation for group $\mathrm{B}$ was $0,08 \pm 0,173 \%$. The mean and standard deviation for group $C$ was $-1,168 \pm 0,534 \%$ The mean and standard deviation for group D was $-0,72 \pm 0,513 \%$ (Table 1). ANOVA one-way test showed there was significant difference mesiodistal width among groups with $\mathrm{p}=0,0001$ $(p<0,05)$. LSD test showed that there were significant difference between group $A$ and $B(p=0,002), A$ and $C$ $(p=0,0001), A$ and $D(p=0,025), B$ and $C(p=0,0001), B$ and $D$ $(\mathrm{p}=0,0001)$ then $\mathrm{C}$ and $\mathrm{D}(\mathrm{p}=0,0001)$ (Table 2$)$.

\section{Abutments Height}

Abutments height dimensional accuracy of group A showed the most inaccurate value was $1,125 \%$, meanwhile the most accurate was $0,25 \%$. For group B, the most inaccurate was $0,375 \%$ and the most accurate was $-0,125 \%$. For group $C$, the most inaccurate was $0,875 \%$, meanwhile the most accurate $0,25 \%$. For group $D$, the most inaccurate was $-1,375 \%$ and the most accurate was $-0,375 \%$. The mean and standard deviation for group A was $0,575 \pm 0,271 \%$. The mean and standard deviation for group B was $0,013 \pm 0,26 \%$. The mean and standard deviation for group $\mathrm{C}$ was $0,55 \pm 0,179 \%$. The mean and standard deviation for group D was $-0,85 \pm 0,444$ $\%$ (Table 3). ANOVA one-way test showed there was significant difference abutments height among groups with $\mathrm{p}=0,0001 \quad(\mathrm{p}<0,05)$. LSD test showed that there were significant difference between group $A$ and $B(p=0,0001), A$ and $D(p=0,0001), B$ and $C(p=0,0001), B$ and $D(p=0,0001)$ then $C$ and $D(p=0,0001)$ except between group A and C, LSD test showed no significant difference $(p=0,855)$. (Table 4). 


\begin{tabular}{|c|c|c|c|c|c|c|c|c|}
\hline \multirow{3}{*}{ Sample No } & \multicolumn{8}{|c|}{ Dimensional Accuracy and Deviation Percentage of Mesiodistal Width } \\
\hline & \multicolumn{2}{|c|}{ Group A } & \multicolumn{2}{|c|}{ Group B } & \multicolumn{2}{|c|}{ Group C } & \multicolumn{2}{|c|}{ Group D } \\
\hline & $\mathbf{m m}$ & $\%$ & $\mathbf{m m}$ & $\%$ & $\mathbf{m m}$ & $\%$ & $\mathbf{m m}$ & $\%$ \\
\hline 1 & 6,18 & $-1,28$ & 6,25 & $0^{* *}$ & 6,14 & $-1,76^{*}$ & 6,16 & $-1,44^{*}$ \\
\hline 2 & 6,15 & $-1,6$ & 6,26 & 0,16 & 6,16 & $-1,44$ & 6,25 & 0 \\
\hline 3 & 6,14 & $-1,76$ & 6,26 & 0,16 & 6,14 & $-1,76$ & 6,18 & $-1,12$ \\
\hline 4 & 6,16 & $-1,44$ & 6,24 & 0,16 & 6,17 & $-1,28$ & 6,2 & $-0,8$ \\
\hline 5 & 6,18 & $-1,12^{* *}$ & 6,25 & $0^{* *}$ & 6,23 & $-0,32^{* *}$ & 6,22 & $-0,48$ \\
\hline 6 & 6,18 & $-1,12^{* *}$ & 6,24 & 0,16 & 6,22 & $-0,48$ & 6,22 & $-0,48$ \\
\hline 7 & 6,14 & $-1,76$ & 6,26 & 0,16 & 6,15 & $-1,6$ & 6,18 & $-1,12$ \\
\hline 8 & 6,14 & $-1,76$ & 6,32 & $0,32 *$ & 6,16 & $-1,44$ & 6,17 & $-1,28$ \\
\hline 9 & 6,13 & $-1,92^{*}$ & 6,32 & $0,32 *$ & 6,21 & $-0,64$ & 6,22 & $-0,48$ \\
\hline 10 & 6,15 & $-1,6$ & 6,25 & $0^{* *}$ & 6,19 & $-0,96$ & 6,25 & $0^{* *}$ \\
\hline$X \pm \mathrm{SD}(\mathrm{mm})$ & \multicolumn{2}{|c|}{$6,249 \pm 0,561$} & \multicolumn{2}{|c|}{$6,265 \pm 0,182$} & \multicolumn{2}{|c|}{$6,177 \pm 0,175$} & \multicolumn{2}{|c|}{$6,205 \pm 0,254$} \\
\hline $\bar{X} \pm$ SD (\%) & \multicolumn{2}{|c|}{$-1,54 \pm 0,28 \%$} & \multicolumn{2}{|c|}{$0,08 \pm 0,173 \%$} & \multicolumn{2}{|c|}{$-1,168 \pm 0,534 \%$} & \multicolumn{2}{|c|}{$-0,72 \pm 0,513 \%$} \\
\hline & & & & $\overline{a n}$ & $\overline{M e}$ & & & \\
\hline
\end{tabular}

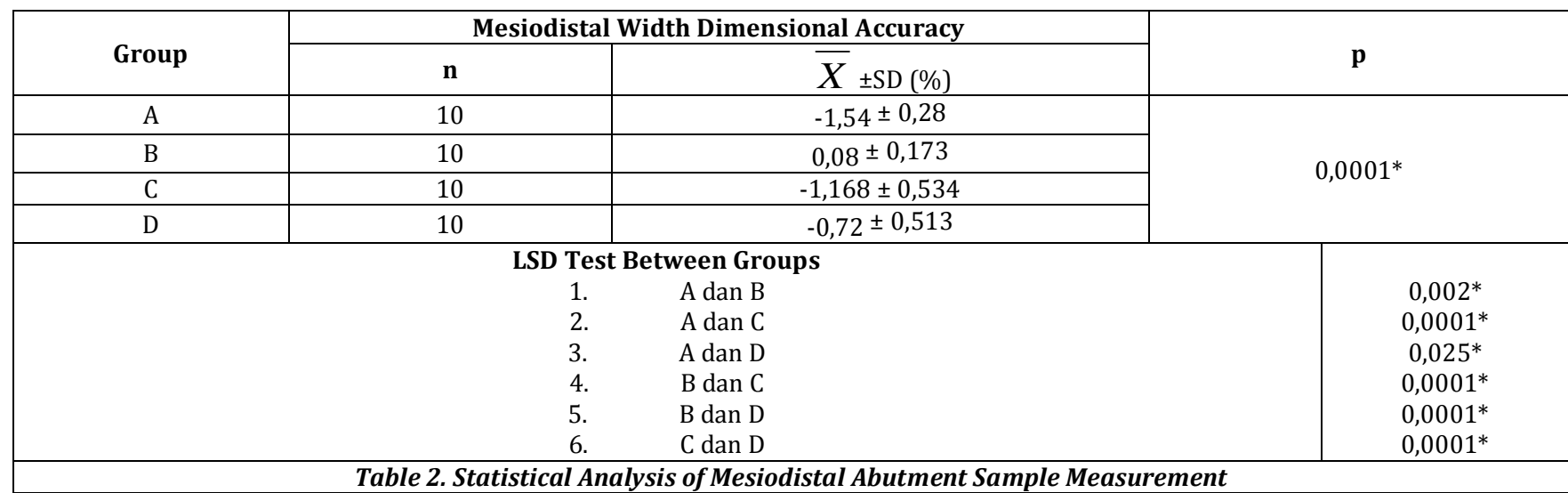

\begin{tabular}{|c|c|c|c|c|c|c|c|c|}
\hline \multirow{3}{*}{ Sample No. } & \multicolumn{8}{|c|}{ Dimensional Accuracy of Abutments Height } \\
\hline & \multicolumn{2}{|c|}{ Group A } & \multicolumn{2}{|c|}{ Group B } & \multicolumn{2}{|c|}{ Group C } & \multicolumn{2}{|c|}{ Group D } \\
\hline & $\mathbf{m m}$ & $\%$ & $\mathbf{m m}$ & $\%$ & $\mathbf{m m}$ & $\%$ & $\mathbf{m m}$ & $\%$ \\
\hline 1 & 8,09 & $1,125^{*}$ & 8,01 & 0,125 & 8,06 & 0,75 & 7,94 & $-0,75$ \\
\hline 2 & 8,03 & 0,375 & 8,03 & $0,375^{*}$ & 8,03 & 0,375 & 7,93 & $-0,875$ \\
\hline 3 & 8,03 & 0,375 & 8,01 & 0,125 & 8,07 & $0,875^{*}$ & 7,89 & $-1,375^{*}$ \\
\hline 4 & 8,05 & 0,625 & 8,01 & 0,125 & 8,04 & 0,5 & 7,97 & $-0,375^{* *}$ \\
\hline 5 & 8,07 & 0,875 & 7,96 & $-0,5$ & 8,01 & $0,25^{* *}$ & 7,92 & -1 \\
\hline 6 & 8,06 & 0,75 & 8,01 & 0,125 & 8,04 & 0,5 & 7,93 & $-0,875$ \\
\hline 7 & 8,04 & 0,5 & 8,02 & 0,25 & 8,05 & 0,625 & 7,91 & $-1,125$ \\
\hline 8 & 8,04 & 0,5 & 7,98 & $-0,25$ & 8,04 & 0,5 & 7,94 & $-0,75$ \\
\hline 9 & 8,02 & $0,25^{\text {** }}$ & 7,99 & $-0,125^{* *}$ & 8,05 & 0,625 & 7,94 & $-0,75$ \\
\hline 10 & 8,03 & 0,375 & 7,99 & $-0,125$ & 8,04 & 0,5 & 7,88 & $-1,5$ \\
\hline $\bar{X} \pm \mathrm{SD}(\mathrm{mm})$ & \multicolumn{2}{|c|}{$8,046 \pm 0,371$} & \multicolumn{2}{|c|}{$8,005 \pm 0,147$} & \multicolumn{2}{|c|}{$8,043 \pm 0,389$} & \multicolumn{2}{|c|}{$7,932 \pm 0,481$} \\
\hline $\bar{X} \pm$ SD (\%) & \multicolumn{2}{|c|}{$0,575 \pm 0,271 \%$} & \multicolumn{2}{|c|}{$0,013 \pm 0,26 \%$} & \multicolumn{2}{|c|}{$0,55 \pm 0,179 \%$} & \multicolumn{2}{|c|}{$-0,85 \pm 0,444 \%$} \\
\hline & & & $A b u$ & Height & Measu & & & \\
\hline
\end{tabular}

\begin{tabular}{|c|c|c|c|}
\hline \multirow{2}{*}{ Group } & \multicolumn{2}{|c|}{ Abutments Height Dimensional Accuracy } & \multirow[b]{2}{*}{$\mathbf{p}$} \\
\hline & $\mathbf{n}$ & $\bar{X} \pm \mathrm{SD}(\%)$ & \\
\hline A & 10 & $0,575 \pm 0,271$ & \multirow{4}{*}{$0,0001^{*}$} \\
\hline $\mathrm{B}$ & 10 & $0,013 \pm 0,26$ & \\
\hline $\mathrm{C}$ & 10 & $0,55 \pm 0,179$ & \\
\hline $\mathrm{D}$ & 10 & $-0,85 \pm 0,444$ & \\
\hline \multicolumn{3}{|c|}{ LSD Test between Groups } & \\
\hline \multicolumn{3}{|c|}{ 7. A dan $B$} & $0,0001^{*}$ \\
\hline \multicolumn{3}{|r|}{ A dan $\mathrm{C}$} & $0,855^{* *}$ \\
\hline \multicolumn{3}{|c|}{ 9. A dan $\mathrm{D}$} & $0,0001^{*}$ \\
\hline \multicolumn{3}{|c|}{ 10. B dan $\mathrm{C}$} & $0,0001 *$ \\
\hline \multicolumn{3}{|c|}{ 11. B dan D } & $0,0001^{*}$ \\
\hline \multicolumn{3}{|c|}{ 12. C dan D } & $0,0001^{*}$ \\
\hline
\end{tabular}




\section{Inter-Abutments Distance}

Inter-abutments dimensional accuracy of group A showed the most inaccurate value was $-0,425 \%$, meanwhile the most accurate was $-0,035 \%$. For group $B$, the most inaccurate was $-0,177 \%$ and the most accurate was $0 \%$. For group $C$, the most inaccurate was $0,814 \%$, meanwhile the most accurate $0,177 \%$. For group D, the most inaccurate was $-0,602 \%$ and the most accurate was $-0,177 \%$. The mean and standard deviation for group A was $-0,216 \pm 0,127 \%$. The mean and standard deviation for group B was $0,177 \pm 0,11$ $\%$. The mean and standard deviation for group $\mathrm{C}$ was $0,57 \pm 0,213 \%$. The mean and standard deviation for group $\mathrm{D}$ was $-0,375 \pm$ $0,141 \%$ (Table 5). ANOVA one-way test showed there was significant difference abutments height among groups with $\mathrm{p}=0,0001$ $(p<0,05)$. LSD test showed that there were significant difference between group A and B $(p=0,0002), A$ and $C(p=0,001), A$ and $D$ $(p=0,0001)$, B and C ( $p=0,0001)$, B and $D(p=0,0001)$ then $C$ and $D(p=0,0001)$ (Table 6).

\begin{tabular}{|c|c|c|c|c|c|c|c|c|}
\hline \multirow{3}{*}{ Sample No. } & \multicolumn{8}{|c|}{ Dimensional Accuracy of Inter-Abutments Distance } \\
\hline & \multicolumn{2}{|c|}{ Group A } & \multicolumn{2}{|c|}{ Group B } & \multicolumn{2}{|c|}{ Group C } & \multicolumn{2}{|c|}{ Group D } \\
\hline & $\mathbf{m m}$ & $\%$ & $\mathbf{m m}$ & $\%$ & $\mathbf{m m}$ & $\%$ & $\mathbf{m m}$ & $\%$ \\
\hline 1 & 28,23 & $-0,071$ & 28,23 & $-0,071$ & 28,44 & 0,673 & 28,18 & $-0,248$ \\
\hline 2 & 28,18 & $-0,248$ & 28,20 & $-0,177$ & 28,45 & 0,708 & 28,08 & $-0,602 *$ \\
\hline 3 & 28,24 & $-0,035^{* *}$ & 28,22 & $-0,106$ & 28,48 & $0,814^{*}$ & 28,17 & $-0,283$ \\
\hline 4 & 28,20 & $-0,177$ & 28,22 & 0,035 & 28,47 & 0,779 & 28,15 & $-0,354$ \\
\hline 5 & 28,22 & $-0,106$ & 28,25 & $0^{* *}$ & 28,45 & 0,708 & 28,20 & $-0,177^{* *}$ \\
\hline 6 & 28,13 & $-0,425^{*}$ & 28,26 & 0,035 & 28,37 & 0,425 & 28,12 & $-0,460$ \\
\hline 7 & 28,15 & $-0,354$ & 28,27 & 0,071 & 28,34 & 0,319 & 28,11 & $-0,496$ \\
\hline 8 & 28,16 & $-0,319$ & 28,30 & $0,177^{*}$ & 28,43 & 0,637 & 28,10 & $-0,531$ \\
\hline 9 & 28,18 & $-0,248$ & 28,29 & 0,142 & 28,30 & $0,177^{* *}$ & 28,18 & $-0,248$ \\
\hline 10 & 28,20 & $-0,177$ & 28,27 & 0,071 & 28,38 & 0,460 & 28,15 & $-0,354$ \\
\hline $\bar{X} \pm \mathrm{SD}(\mathrm{mm})$ & \multicolumn{2}{|c|}{$28,189 \pm 0,564$} & \multicolumn{2}{|c|}{$28,255 \pm 0,212$} & \multicolumn{2}{|c|}{$28,411 \pm 0,344$} & \multicolumn{2}{|c|}{$28,144 \pm 0,417$} \\
\hline$X \pm \mathrm{SD}(\%)$ & \multicolumn{2}{|c|}{$-0,216 \pm 0,127 \%$} & \multicolumn{2}{|c|}{$0,177 \pm 0,11 \%$} & \multicolumn{2}{|c|}{$0,57 \pm 0,213 \%$} & \multicolumn{2}{|c|}{$-0,375 \pm 0,141 \%$} \\
\hline \multicolumn{9}{|c|}{ Table 5. Inter-Abutment Distance Sample Measurement } \\
\hline
\end{tabular}

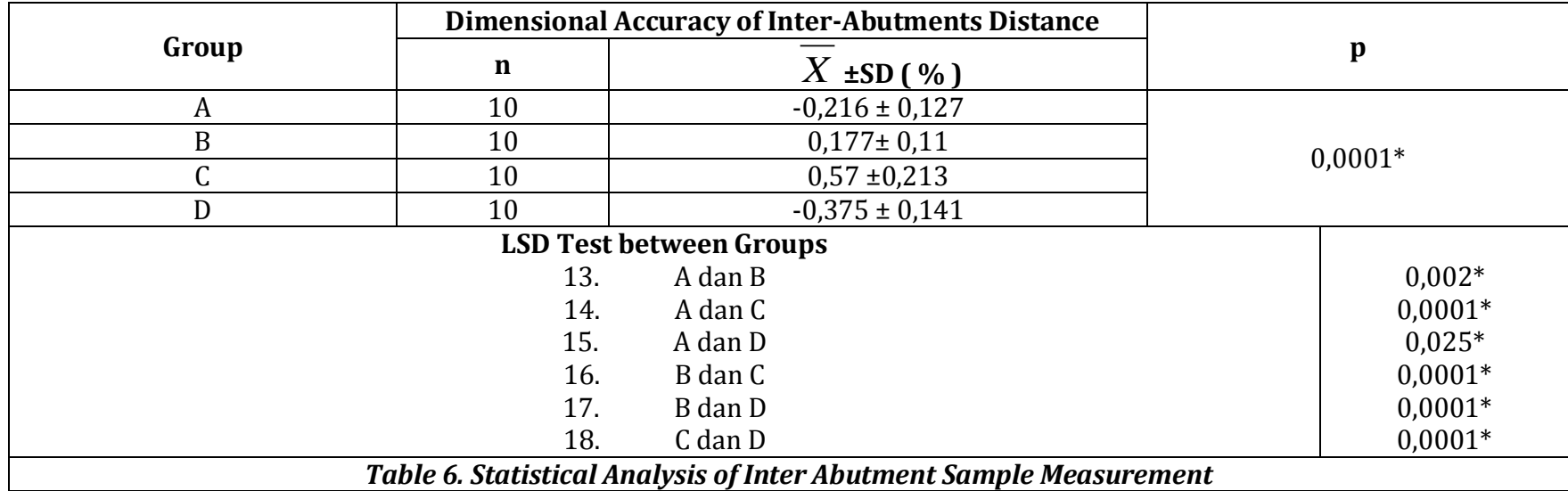

\section{DISCUSSION}

From this study, it was found that each sample has different dimensional accuracy value for mesiodistal width, height and inter-abutment distance. It was possibly caused by shrinkage occurred after polymerization of polyvinyl siloxane material, imperfect elastic recovery of polyvinyl siloxane material and expansion of hard stone gyps. Suparaneni et al (2013) stated that shrinkage occurred after polymerization is one of factor affecting variations of dimensional accuracy measurement. The shrinkage varies from $0,02 \%$ to $0,05 \%$ and greater in low viscosity materials because of the amount of filler contained in it.11 Agroudi and Essam (2010) reported that polymerization process which included the cross-linking of polymer chain can reduced spatial volume. Polymerization reaction continued for a while after setting and still continue after the impression was taken out, even, the low viscosity material has greater constriction after polymerization.12 Rajapur et al (2012) stated that the main cause of impression distortion was polymerization shrinkage of the impression material. Polymerization caused reduction of spatial volume which caused dimensional changes of impression. The dimensional change direction depends on the bonding of impression material and impression tray. Elastic recovery is the nature of polyvinyl siloxane to return to its original shape after stretching so that the material can be larger or smaller. ${ }^{13}$ Caputi and Varvara (2008) stated that putty elastic recovery occurred when the impression was taken out, it would pulled wash material which can lead to increase the inter-abutment distances. ${ }^{14}$ Meanwhile, Mahdi (2016) stated that two step putty-wash impression technique had elastic recovery from putty material when it was reseated on master model at the second step of impression, which caused pressure on putty lead on dimensional change of putty. After setting and pulled out, higher viscosity material tempted to return to its original shape because of its elastic recovery characteristic so that the inter-abutment distance became wider. ${ }^{15}$

This study also shown that there was one sample of dimensional accuracy of inter-abutment distance of Group B which shown $0 \%$. It could possibly be caused by some factors such as the bulk of wash material of $2 \mathrm{~mm}$ was uniformly obtained on entire impression surface. Mubashir et al (2015) 
stated in his study that a $2 \mathrm{~mm}$ wash bulk produced the most accurate impression. Wash bulk less or more than $2 \mathrm{~mm}$ could have distortion when the impression pulled out 16 . Uniform bulk of impression material lead to evenly distributed shrinkage so that the result would be more accurate. In Group B, which used spacer covered all the surface, so that the wash material can imprint all the surface and produced more accurate impression. Wash material can imprint in high accuracy up to $25 \mu \mathrm{m}$, because if wash is a material with low viscosity, whereas this material has low amount of filler which can produce impression with high accuracy. ${ }^{17}$

Table3shown that all Group A and C samples increased in abutment height, all Group D samples decreased in abutment height meanwhile some samples of Group B increased, and others decreased. The increase in abutment height of Group A and $\mathrm{C}$ possibly caused by the shrinkage of the impression materials towards to impression tray and the wash trapped in impression tray. These findings similar to previous studies done by Sayed et al (2015), Agroudi and Essam (2010) and Caputi and Varvara (2008) who reported that when making impression using one step conventional technique, will occur increase in abutment height cause by the shrinkage and constriction of impression material towards impression tray especially area around abutment so that the impression material pulled towards the impression tray. This also happen to two step conventional impression technique. Agroudi and Essam (2010) also reported the same thing. Sayed et al (2015) reported that abutment height increase occurred because impression material trapped in impression tray and could not come out and increase the abutment height. 1,13,15 the decrease of abutment height occurred at all Group D samples, possibly caused by uneven wash bulk in impression. This findings similar to previous study done by Dugal et al (2013) and Chugh et al (2012) who stated that two step impression technique using polyethylene spacer $(0,5 \mathrm{~mm})$ will decrease in abutment height because of the spacer was folded when the impression was taken especially at the top of abutment so that the wash bulk is uneven. 7,18

Group B samples measurement vary because of elastic recovery characteristic of the impression material. Imperfect elastic recovery from impression material can cause the abutment height increase or decrease. Mahdi (2016) reported that the setting putty, when reseated with wash material, will get pressure from the wash and become distort. After setting and pulled out, the impression with higher viscosity tempted to return to its original shape because of its elastic recovery. ${ }^{16}$

Table 1 also shown samples from Group B and D which had $0 \%$ deviation, meant that the mesiodistal width of the samples were equal with master model. It was possibly caused by the bulk of the impression as thick as $2 \mathrm{~mm}$ which produced the most accurate sample. These findings similar to previous study done by Mubashir et al (2015) stated that the wash bulk less or more than $2 \mathrm{~mm}$ will make impression distort when pulled out. 17 the second factor is the uniform wash bulk on all surface make shrinkage more even and the result will be more accurate. ${ }^{19}$ The third factor is the accuracy of wash material. In group B used spacer which covered all of the surface so that the wash material can imprint all surface and the impression will be more accurate. Wash material can imprint with high accuracy up to $25 \mu \mathrm{m}$ because wash is a low viscosity material whereas this material has low amount of filler so that the result will be more accurate. ${ }^{19}$ Meanwhile in group D, possibly caused by when the impression was taken, the polyethylene spacer didn't fold so that the bulk is uniform all over the surface.

From ANOVA one-way analysis, this study show there is significant difference among groups $(\mathrm{p}=0,0001)$. The LSD test showed significant difference between group $A$ and $B$, group $A$ and $C$, group $A$ and $D$, group $B$ and $C$, group $B$ and D along with group $C$ and $D(p<0,05)$. This difference possibly caused by superiority and inferiority of each impression techniques used in this study. In group A which used one step conventional putty-wash impression technique, this technique cannot control the wash bulk properly so that the wash bulk uneven in all impression surface. Wu and Donovan (2007) stated that when using one step conventional, the impression will be carried out with putty than wash more often so that the result will be less accurate. The inferiority of this technique can be overcome with modification by using a ethyl vinyl acetate spacer. The $2 \mathrm{~mm}$ and rigid of ethyl vinyl acetate spacer will create space for wash material ${ }^{20}$. In Mubashir et al (2015) study, $2 \mathrm{~mm}$ of wash bulk produced the most accurate impression compare to $4 \mathrm{~mm}^{17}$. The same findings found in Chugh et al (2012) study. In their study, 1 $\mathrm{mm}$ and $2 \mathrm{~mm}$ spacer thickness produced the most accurate impression compared to without spacer and polyethylene spacer. ${ }^{7}$ The two-step impression technique cannot produce enough and uniform space for wash material. The inaccuracy of this technique is due to wash is trapped in and cannot flow out. ${ }^{1}$ Two-step impression technique using polyethylene spacer cannot control the uniform of wash bulk because it can be folded during the impression taking. ${ }^{7}$

Only LSD test between group A and C showed insignificant difference, it is possibly because of the inferiority of one step and two step conventional impression technique which cannot provide enough space for wash and the wash bulk is uneven lead to distortion on the result.

Table 1 and table 2 showed mean and standard deviation of each group, whereas the smallest value was the most accurate technique, so that it could be concluded that group B (One step modification putty-wash impression technique using ethyl vinyl acetate as spacer) was the most accurate impression technique in mesiodistal width, followed by group D (Two step putty-wash impression technique using polyethylene as spacer), group C (Two step putty-wash impression technique without spacer) and the most inaccurate was group A (One step conventional putty-wash impression technique). It was possibly caused by the ability of one step modification putty-wash impression technique in control the wash bulk of $2 \mathrm{~mm}$ all over the impression surface so that the result was more accurate.

Table 3 and table 4 showed mean and standard deviation of each group, whereas the smallest value was the most accurate technique, so that it could be concluded that group B (One step modification putty-wash impression technique using ethyl vinyl acetate as spacer) was the most accurate impression technique in abutment height, followed by group C (Two step putty-wash impression technique without spacer), group A (One step conventional putty-wash impression technique ), and the most inaccurate was group D (Two step putty-wash impression technique using polyethylene as spacer). It was possibly caused by the ability of one step modification putty-wash impression technique in 
control the wash bulk of $2 \mathrm{~mm}$ all over the impression surface so that the result was more accurate.

Table 5 and table 6 showed mean and standard deviation of each group, whereas the smallest value was the most accurate technique, so that it could be concluded that group B (One step modification putty-wash impression technique using ethyl vinyl acetate as spacer) was the most accurate impression technique in inter-abutment distance, followed by group A (One step conventional putty-wash impression technique), group D (Two step putty-wash impression technique using polyethylene as spacer), and the most inaccurate was group C (Two step putty-wash impression technique without spacer). It was possibly caused by the ability of one step modification putty-wash impression technique in control the wash bulk of $2 \mathrm{~mm}$ all over the impression surface.

\section{CONCLUSION}

One step modification putty-wash impression technique using ethyl vinyl acetate as spacer is the most accurate technique in mesiodistal width, abutment height and inter abutment distance dimension as it had the smallest deviation percentage $(0 \%)$. Although it was the best, the results of this technique also had distortion, but it was not so much, with increase in mesiodistal width, abutment height and interabutment distance which is possibly caused by stone gips expansion which cannot be compensated by the shrinkage of impression material after polymerization.

\section{REFERENCES}

[1] Sayed NM, Aly NH, Rayyan MM. The effect of different double-step impression techniques on accuracy of stone dies. Egyptian Dent J 2015;61:641-50.

[2] Leao MP, Pinto CP, Sponchiado AP, et al. Dimensional stability of a novel polyvinyl siloxane impression technique. Braz J Oral Sci 2014;13(2):118-23.

[3] Pandey A, Mehtra A. Comparative study of dimensional stability and accuracy of various elastomeric materials. IOSR J Dent \& Med Sci 2014;13(3):40-5.

[4] Shiozawa M, Takahashi H, Finger WJ, et al. Effects of the space for wash materials on sulcus depth reproduction with addition-curing silicone using twostep putty-wash technique. Dent Mat J 2013;32(1):150-5

[5] Pandita A, Jain T, Yadav NS, et al. Evaluation and comparison of dimensional accuracy of newly introduced elastomeric impression material using 3D laser scanners: an in-vitro study. J Contemp Dent Pract 2013;14(2):265-8.
[6] Chugh A, Arora A, Singh VP. Accuracy of different putty-wash impression technique with various spacer thickness. Int J Clin Pediatric Dent 2012;5(1):33-8.

[7] Bansal PK. Comparison of dimensional accuracy using two elastomeric impression materials in fixed prosthodontics. Pakistan Oral \& Dent J 2010;30(2):537-44.

[8] Faria ACL, Rodrigues RCS, Macedo AP, et al. Accuracy of stone casts obtained by different impression materials. Braz Oral Res 2008;22(4):293-8.

[9] Luthardt RG, Walter MH, Koch R, et al. Clinical parameters influencing the accuracy of 1- and 2- stage impressions: a randomized controlled trial. Int $\mathrm{J}$ Prosthodontics 2008;21(4):322-7.

[10] Jevremovic D, Trifkovic B, Lapcevic A, et al. The use of CAD/CAM technology in design and manufacture of thin laminate veneers. Manuf and Ind Eng 2012;11(3):54-6.

[11] Surapaneni H, Samatha PY, Shankar RY, et al. Polyvinyl siloxane in dentistry: an overview. Trends Biomater Artif Organs 2013;27(3):115-23.

[12] El-Agroudi M, Essam E. Accuracy of working cast and dies produced by fast-setting polyvinyl siloxane impressions. J Am Sci 2010;6(11):284-92.

[13] Rajapur A, Dixit S, Hoshing C, et al. The influence of tray spacer and repeat pours on the accuracy of monophasic polyvinylsiloxane impression. J Contemp Dent Pract 2012;13(6):824-9.

[14] Caputi S, Varvara G. Dimensional accuracy of resultant casts made by a monophase, one-step and two-step and a novel two-step putty/light-body impression technique: an in vitro study. J Prosthet Dent 2008;99(4):274-81.

[15] Mahdi NA. Comparative evaluation of the dimensional accuracy of different putty-wash techniques using additional silicone impression material: in vitro study. J of Al Rafidian University College 2016;38(1):141-61.

[16] Mubashir AS, Motwani BK, Sahu S, et al. Dimensional accuracy \& stability of silicone putty-wash impression technique with different thickness of light body material. J Cont Med A Dent 2015;3(1):81-4.

[17] Kumari N, Nandeeshwar DB. The dimensional accuracy of polyvinyl siloxane impression materials using two different impression techniques: an in vitro study. J Indian Prosthodont Soc 2015;15(3):211-7.

[18] Dugal R, Railkar B, Musani S. Comparative evaluation of dimensional accuracy of different polyvinyl siloxane putty-wash impression technique-in vitro study. J of Int Oral Health 2013;5(5):85-94.

[19] Mishra SK, Hazari P, Chowdhary R, et al. A modified technique for making putty-wash two-step impression. BLDE Univ J Health Sci 2017;2(1):55-8. 